\title{
PEMBINAAN SOFT SKILL \\ GURU MELALUI KEGIATAN \\ HALAQOH UNTUK SUKSESI PPA \\ DI SD AL-IRSYAD AL-ISLAMIYYAH \\ PURWOKERTO
}

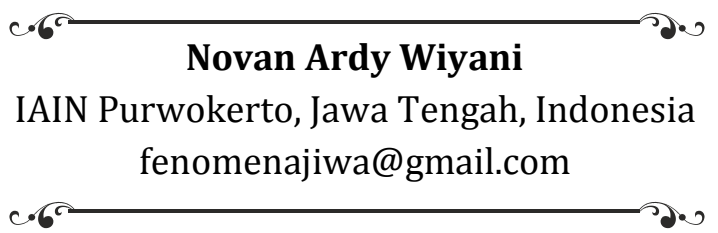

\begin{abstract}
This research is a qualitative research aimed to describe management process in guiding teacher soft skill through halaqoh activity for PPA succession in SD al-Irsyad al-Islamiyyah Purwokerto. The results showed four findings. First, the planning of teacher's soft skill development through halaqoh activities is done by formulating halaqoh objectives, formulating teacher standardization, preparing halaqoh agenda, halaqoh officer schedule and halaqoh SOP. Second, the organizing of teacher's soft skill activities through halaqoh activities is done by assigning tasks to principals, musyrif and mu'allim. Third, the benefits gained from the implementation of this guidance activity is the quality and quantity of worship and the recitation of controlled teacher's Quran. It makes teacher soft skill renewable and has implications for the success of the Program of Morals Education for students. Fourth, controlling activities are carried out by the principal and mu'allim. The principal controls the presence of the teacher on halaqoh activities, while the mu'allim controls tahsin and tahfidz activities as well as the daily worship of the teacher.
\end{abstract}

Keywords: soft skill, teacher, halaqoh.

Abstrak: Penelitian ini merupakan penelitian kualitatif yang bertujuan untuk mendeskripsikan proses manajemen dalam membimbing soft skill guru melalui kegiatan halaqoh untuk suksesi AKP di SD al-Irsyad al-Islamiyyah Purwokerto. Hasilnya 


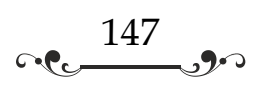

menunjukkan empat temuan. Pertama, perencanaan pengembangan soft skill guru melalui kegiatan halaqoh dilakukan dengan merumuskan tujuan halaqoh, merumuskan standarisasi guru, menyusun agenda halaqoh, jadwal petugas halaqoh dan SPS halaqoh. Kedua, pengorganisasian kegiatan soft skill guru melalui kegiatan halaqoh dilakukan dengan menugaskan tugas kepada kepala sekolah, musyrif dan mu'allim. Ketiga, manfaat yang didapat dari pelaksanaan kegiatan bimbingan ini adalah kualitas dan kuantitas ibadah dan pembacaan al-Quran guru terkontrol. Hal itu membuat soft skill guru terbarukan dan berimplikasi pada keberhasilan Program Pendidikan Moral bagi siswa. Keempat, kegiatan pengendalian dilakukan oleh kepala sekolah dan mu'allim. Kepala sekolah mengendalikan kehadiran guru dalam kegiatan halaqoh, sedangkan para mu'allim mengendalikan kegiatan tahsin dan tahfidz serta penyembahan guru setiap hari.

Kata Kunci: soft skill, guru, halaqoh

\section{A. Pendahuluan}

Pada hakikatnya, fungsi dan tujuan penyelenggaraan pendidikan di setiap jenjang, dari jenjang pendidikan anak usia dini, pendidikan dasar, hingga pendidikan menengah adalah membentuk karakter peserta didik. Hal ini sesuai dengan kebijakan pemerintah yang tertuang dalam Undang-Undang RI Nomor 20 tahun 2003 tentang Sistem Pendidikan Nasional.

Pada Pasal 3 dalam Undang-Undang RI tersebut disebutkan bahwa pendidikan nasional berfungsi mengembangkan kemampuan dan membentuk watak serta peradaban bangsa yang bermartabat dalam rangka mencerdaskan kehidupan bangsa, yang bertujuan untuk berkembangnya potensi peserta didik agar menjadi manusia yang beriman dan bertaqwa kepada Tuhan Yang Maha Esa, berakhlak mulia, sehat, berilmu, cakap, kreatif mandiri, dan menjadi warga negara yang demokratis serta bertanggungjawab.

Namun sayangnya, diakui ataupun tidak belum sepenuhnya lembaga pendidikan mau dan mampu menyelenggarakan layanan pendidikan yang mengarah pada pembentukan karakter peserta didik. SD al-Irsyad al-Islamiyyah Purwokerto merupakan salah satu 


\section{reces}

SD Islam yang memiliki kemauan dan kemampuan untuk menyelenggarakan layanan pendidikan yang fokus pada pembentukan karakter peserta didiknya.

SD al-Irsyad al-Islamiyyah Purwokerto memiliki program pembentukan karakter yang diberi istilah PPA atau Program Pendidikan Akhlak. Ada tiga tujuan yang hendak diraih dari PPA. Pertama, agar anak bisa belajar secara utuh tentang agama Islam. Kedua, untuk mencegah sekulerisme. Ketiga, untuk membentuk pribadi muslim. Ekspektasi yang ingin didapat dari pencapaian ketiga tujuan tersebut adalah agar akhlakul karimah dapat mewarnai semua aktivitas peserta didik baik di lingkungan sekolah maupun di lingkungan keluarga dan masyarakat.

Ketercapaian ekspektasi dari ketiga tujuan di atas didukung oleh tiga komponen utama. Pertama, SDM sekolah, dalam hal ini adalah guru harus memiliki skill (kemampuan) yang dibutuhkan untuk mensukseskan PPA dan mampu menjadi teladan bagi peserta didik. Kedua, orang tua, di mana mereka juga harus memiliki skill dan bisa menjadi teladan bagi anak-anaknya. Ketiga, peserta didik yang memiliki pemahaman dan skill untuk ber-akhlakul karimah.

Guru menjadi komponen yang paling utama di antara ketiga komponen tersebut. Ini karena suksesi sekolah dalam PPA sangat ditentukan oleh skill dan keteladanan guru. Untuk mendukung hal itu, maka pihak LPP al-Irsyad al-Islamiyyah Purwokerto bekerjasama dengan pihak sekolah mengadakan kegiatan halaqoh bagi para guru. Upaya tersebut dilakukan agar soft skill guru dapat terbina dan dikembangkan untuk kepentingan suksesi PPA di SD al-Irsyad alIslamiyyah Purwokerto.

Berdasarkan latar belakang masalah di atas, maka rumusan masalah dalam penelitian ini adalah "bagaimana pembinaan soft skill guru melalui kegiatan halaqoh untuk suksesi PPA di SD al-Irsyad alIslamiyyah Purwokerto?". Sedangkan sub rumusan masalah dalam penelitian ini yaitu:

a. Bagaimana perencanaan kegiatan pembinaan soft skill guru melalui kegiatan halaqoh untuk suksesi PPA di SD al-Irsyad alIslamiyyah Purwokerto? 


$$
\text { reces }
$$

b. Bagaimana pengorganisasian kegiatan pembinaan soft skill guru melalui kegiatan halaqoh untuk suksesi PPA di SD al-Irsyad alIslamiyyah Purwokerto?

c. Bagaimana pelaksanaan kegiatan pembinaan soft skill guru melalui kegiatan halaqoh untuk suksesi PPA di SD al-Irsyad alIslamiyyah Purwokerto?

d. Bagaimana pengontrolan kegiatan pembinaan soft skill guru melalui kegiatan halaqoh untuk suksesi PPA di SD al-Irsyad alIslamiyyah Purwokerto?

Tujuan dari dilaksanakannya penelitian ini adalah untuk mendeskripsikan proses manajemen dalam pembinaan soft skill guru melalui kegiatan halaqoh untuk suksesi PPA di SD al-Irsyad alIslamiyyah Purwokerto. Sedangkan manfaat yang dapat diperoleh dari penelitian ini antara lain:

a. Secara konseptual, penelitian ini dapat menghasilkan konsep manajemen pembinaan soft skill guru untuk membentuk karakter peserta didik SD/MI.

b. Secara praktis, hasil penelitian ini dapat dijadikan sebagai guideline oleh SD/MI lain dalam melakukan pembinaan soft skill guru-gurunya.

Penelitian ini merupakan jenis penelitian lapangan dengan menggunakan pendekatan penelitian kualitatif. Sumber data utama dalam penelitian ini adalah penanggungjawab bidang biah islamiyyah. Ia bertugas sebagai koordinator dalam pelaksanaan kegiatan halaqoh bagi guru SD al-Irsyad al-Islamiyyah Purwokerto. Data dalam penelitian ini dikumpulkan dengan wawancara, dokumentasi, dan observasi. Sedangkan teknik analisis data yang digunakan adalah teknis analisis data secara induktif (Moleong, 2012: 10).

\section{B. Pembahasan}

\section{Urgensi Soft skill bagi Guru}

Mudlofir (2012) mengungkapkan bahwa kata soft skill seringkali disandingkan dengan hard skill. Hard skill atau hard competency merupakan gambaran perilaku pada diri seseorang yang dapat dilihat dengan mata. Hard skill adalah skill yang dapat menghasilkan sesuatu yang sifatnya visible dan immediate. Hard skill 


\section{r.e.c. 150}

dapat dinilai dari technical test atau practical test. Unsur hard skill dapat dilihat dari intelligence quotion thinking yang mempunyai indikator kemampuan menghitung, menganalisa, mendesain, wawasan dan pengetahuan yang luas, membuat model dan kritis. Hard skill juga merupakan keterampilan teknis yang dimiliki oleh seseorang dalam menjalankan profesinya.

Sementara soft skill merupakan keterampilan non-teknis. Wujud soft skill seperti kejujuran, tanggung jawab, berlaku adil, kemampuan bekerja sama, kemampuan beradaptasi, kemampuan berkomunikasi, toleran, hormat terhadap sesama, kemampuan mengambil keputusan, dan kemampuan memecahkan masalah.

Setiap orang dengan profesi apapun harus memiliki hard skill dan soft skill. Profesi guru misalnya, guru harus memiliki hard skill yang ditunjukkan dengan kompetensi pedagogik dan kompetensi profesionalnya. Namun di sisi yang lain guru juga harus memiliki soft skill yang ditunjukkan dengan kompetensi kepribadian dan kompetensi sosialnya. Soft skill yang dimiliki oleh guru akan melandasi hard skill yang dimilikinya.

Mudlofir (2012) mengungkapkan bahwa ada dua komponen dalam soft skill guru, yaitu:

a. Komponen intrapersonal

Komponen intrapersonal pada dasarnya merupakan kemampuan yang dimiliki oleh guru dalam mengendalikan dirinya ketika bekerja untuk mencapai tujuan pendidikan yang telah ditentukan. Dengan pengendalian diri tersebut ia memiliki kemampuan berikut:

1) Mampu memotivasi dirinya sendiri untuk konsisten dalam bekerja (motivasi internal).

2) Mampu sadar diri (self awarness) untuk selalu fokus meraih tujuan pendidikan.

3) Mampu berpikir positif terhadap berbagai perilaku yang ditampilkan oleh orang lain dalam kegiatan pendidikan.

4) Mampu berkonsentrasi dalam bekerja.

5) Mampu memberikan teladan bagi peserta didiknya serta pihak lain.

b. Komponen interpersonal 


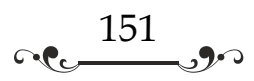

Komponen interpersonal merupakan kemampuan yang dimiliki oleh guru dalam menjalin relasi dengan pihak lain, seperti dengan peserta didik, wali murid, rekan sejawat dan masyarakat. Dengan kemampuan dalam menjalin relasi guru dapat:

1) Berkomunikasi dengan pihak lain untuk kepentingan pendidikan.

2) Melakukan koordinasi dengan pihak lain agar bisa bekerja sama dalam meraih tujuan pendidikan

3) Membangun tim kerja untuk mencapai tujuan pendidikan.

4) Mampu mengelola konflik di lingkungan kerjanya.

Berdasarkan deskripsi di atas dapatlah disimpulkan bahwa hard skill erat kaitannya dengan kecerdasan intelektual (intellegence quotient/IQ), sedang soft skill erat kaitannya dengan kecerdasan emosional dan spiritual (emotional and spiritual quotient/ESQ). Kesuksesan seorang dalam bekerja $80 \%$ dipengaruhi oleh soft skill yang dimilikinya dan $20 \%$ dipengaruhi oleh hard skill yang dimilikinya. Hal ini juga berlaku bagi guru. Kemampuan guru dalam mewujudkan fungsi dan tujuan pendidikan sangat dipengaruhi oleh kepemilikan soft skill-nya.

Tobroni mengungkapkan (2015: 232) bahwa soft skill yang diidentikkan dengan kecerdasan emosional dan spiritual memiliki hubungan dengan profesionalitas kerja guru. Dilihat dari motivasi kerjanya, guru dalam melaksanakan tugasnya dibedakan menjadi dua, yaitu:

a. Guru yang bekerja sebagai sarana mencari nafkah dan kehormatan

Guru seperti ini akan bekerja dengan motivasi keduniawian. Hal itu akan mendorongnya berperilaku transaksional. Akibatnya jiwa pengabdian, kepedulian, pengorbanan, dan pelayanan yang diberikan kepada peserta didiknya dan masyarakatnya terbatas, bahkan cenderung menuntut dan mendahulukan hak-haknya daripada menunaikan kewajiban-kewajibannya.

b. Guru yang bekerja karena pengabdian kepada Allah SWT dan untuk mendapatkan ridhoNya

Guru seperti ini bekerja karena sebuah panggilan keimanannya kepada Allah SWT dan dalam rangka mengharap ridhoNya. Guru seperti ini akan memiliki kekuatan pendorong, daya tahan, dan 


\section{recus 152}

energi ganda dalam mengemban tugasnya dan dalam menghadapi perubahan.

Guru tidak bekerja secara transaksional tetapi lebih bersifat altruistik. Sifat altruistik muncul dari keterpanggilan keimanannya kepada Tuhannya dan pekernan Tuhannya. Guru akan mendidik peserta didiknya dengan penuh keikhlasan dan bekerja dengan penuh kualitas. Kedua hal itu akan sangat berpengaruh pada profesionalitas kerjanya sebagai seorang guru.

Pada dasarnya guru yang memiliki soft skill kuat akan memiliki kepribadian yang matang pula. Chaerul Rochman dan Heri Gunawan (2012: 35) mengungkapkan bahwa guru yang memiliki soft skill yang kuat akan banyak berpengaruh terhadap perkembangan peserta didiknya, terutama perkembangan mental dan spiritual peserta didiknya. Pengaruh tersebut ditularkan melalui pemberian teladan kepada peserta didiknya.

\section{Pembinaan Guru}

Guru adalah bapak rohani (spiritual father) bagi peserta didiknya. Guru memberikan santapan jiwa dengan ilmu, pembinaan akhlak mulia dan meluruskannya. Guru menjadi pihak yang sangat menentukan terhadap keberhasilan berbagai program pendidikan yang dicanangkan oleh sekolah (Sulistyorini, 2009: 72).

Hal itu menjadikan guru dituntut untuk memiliki berbagai kompetensi (kemampuan) yang dibutuhkan untuk mendidik peserta didiknya. Kompetensi-kompetensi tersebut seperti kompetensi di bidang kognitif, kompetensi di bidang performance, dan kompetensi di bidang sikap (Ramayulis dan Samsul Nizar, 2009: 153). Kompetensi di bidang sikap ini berhubungan dengan soft skill guru.

Soft skill guru menjadi suatu hal yang perlu diperbaharui. Ini karena soft skill berhubungan dengan keadaan hati yang bolak-balik. Meskipun guru disebut sebagai bapak ruhani (spiritual father) namun guru juga seperti manusia lainnya. Guru membutuhkan pembinaan dari pihak lain agar ia menjadi pribadi yang istiqomah untuk berperilaku positif dalam kehidupannya di lingkungan keluarga, lingkungan sekolah dan lingkungan masyarakatnya.

Pembinaan guru pada dasarnya merupakan usaha-usaha untuk mendayagunakan, memajukan, dan meningkatkan produktivitas kerja guru di sekolah. Tujuan dari kegiatan pembinaan 


\section{reces 153}

guru adalah agar tumbuh kemampuan pada setiap guru yang meliputi perkembangan keilmuannya, wawasan berpikirnya, keterampilannya dalam mengajar, serta soft skill yang dibutuhkannya dalam mendidik peserta didiknya sehingga produktivitas kerja dapat ditingkatkan (Salam, 2014: 188).

Ada lima prinsip yang harus diperhatikan dalam pelaksanaan pembinaan guru, yaitu:

a. Pembinaan guru patut dilakukan untuk semua guru, tanpa terkecuali.

b. Pembinaan guru berorientasi pada perubahan sikap (soft skill) dalam rangka peningkatan produktivitas kerja guru.

c. Pembinaan guru dilaksanakan untuk mendorong meningkatnya kontribusi setiap guru terhadap program sekolah.

d. Pembinaan guru diarahkan untuk mendidik dan melatih guru agar ia memiliki kompetensi unutk mensukseskan program sekolah.

e. Pembinaan guru dirancang dan dilaksanakan untuk merespon berbagai perubahan dan tantangan yang dihadapi oleh sekolah (Salam, 2014: 189).

Ada tiga faktor dominan yang dapat menentukan keberhasilan dalam pelaksanaan pembinaan guru. Kedua faktor tersebut yaitu:

a. Jalur atau wadah sebagai wahana untuk melaksanakan pembinaan guru. Jalur atau wadah tersebut harus jelas.

b. Substansi atau materi yang dijadikan sebagai bahan pembinaan harus betul-betul bermanfaat dalam membina pola pikir, keterampilan mendidik, serta soft skill guru (Wahjosumidjo, 2011: 244).

c. Tujuan dari kegiatan pembinaan harus relevan dengan programprogram yang dicanangkan oleh sekolah. Harapannya program pembinaan tersebut dapat memberikan kontribusi terhadap keberhasilan atau kesuksesan program-program sekolah yang sedang dilaksanakan.

Untuk memastikan agar kegiatan pembinaan guru dapat berlangsung efektif dan efisien, maka perlu dilakukan empat kegiatan manajerial yang mencangkup:

a. Perencanaan kegiatan pembinaan guru 


$$
\text { rece } 154 \text {, }
$$

Pada perencanaan kegiatan pembinaan guru dilakukan proses berpikir dan penentuan secara matang serta penuangan secara tertulis mengenai hal-hal yang akan dikerjakan di masa mendatang dalam rangka mencapai tujuan kegiatan pembinaan guru.

Langkah-langkah yang dilakukan dalam perencanaan kegiatan pembinaan guru antara lain:

1) Memprediksi keadaan dan kebutuhan terkait dengan pelaksanaan pembinaan guru di kemudian hari.

2) Menentukan tujuan yang hendak dicapai dalam kegiatan pembinaan guru.

3) Menentukan kebijakan yang akan ditempuh dalam mencapai tujuan yang telah ditetapkan.

4) Menyusun program kegiatan pembinaan guru, termasuk di dalamnya pendekatan yang ditempuh, serta jenis dan urutan kegiatan yang akan dilaksanakan.

5) Menentukan biaya yang dibutuhkan.

6) Menentukan waktu dan jadwal/alokasi waktu kegiatan, baik secara keseluruhan maupun pada setiap sub kegiatan (Masyhud, 2014: 129).

b. Pengorganisasian kegiatan pembinaan guru

Pengorganisasian kegiatan pembinaan guru dapat diartikan sebagai keseluruhan proses pengelompokkan dan penempatan orang-orang, alat-alat, tugas-tugas dan tanggung jawab serta wewenang yang ada dalam rangka melaksanakan kegiatan pembinaan guru untuk mencapai tujuan pembinaan guru yang telah ditetapkan.

Langkah-langkah yang dilakukan dalam pengorganisasian pembinaan guru antara lain:

1) Mengidentifikasi jenis-jenis tugas, tanggung jawab, dan wewenang yang ada di sekolah.

2) Menggolong-golongkan jenis-jenis tugas, tanggung jawab dan wewenang yang ada tersebut berdasarkan karakteristiknya.

3) Menentukan dan mendistribusikan tugas, tanggung jawab, dan kewenangan yang ada kepada setiap orang di sekolah.

4) Mengidentifikasi dan menentukan semua sumber yang ada, baik sumber manusia maupun sumber non-manusia. 


$$
\text { reces }
$$

5) Merumuskan aturan-aturan dan hubungan kerja pada setiap orang atau unit organisasi sekolah yang ada (Masyhud, 2014: 130).

c. Pelaksanaan kegiatan pembinaan guru

Pelaksanaan kegiatan pembinaan guru merupakan kegiatan untuk merealisasikan rencana kegiatan pembinaan guru yang telah ditetapkan agar tujuan dari kegiatan pembinaan guru dapat tercapai. Dalam pelaksanaannya, pihak-pihak yang terlibat dalam kegiatan pembinaan guru bekerja sesuai dengan jadwal maupun prosedur yang telah ditetapkan.

d. Pengontrolan kegiatan pembinaan guru

Pengontrolan kegiatan pembinaan guru dapat diartikan sebagai suatu proses pengamatan terhadap pelaksanaan kegiatan pembinaan guru di sekolah untuk menjamin agar semua aktivitas yang sedang dilaksanakan berjalan sesuai dengan rencana kegiatan pembinaan guru yang telah ditentukan sebelumnya.

Kegiatan-kegiatan yang dilakukan dalam pengontrolan kegiatan pembinaan guru antara lain:

1) Mencegah terjadinya penyimpangan-penyimpangan dari rencana yang telah ditetapkan sebelumnya.

2) Meluruskan kembali penyimpangan-penyimpangan yang terjadi dalam proses pelaksanaan.

3) Membimbing pihak-pihak yang terlibat dalam pelaksanaan kegiatan pembinaan guru agar terjadi peningkatan produktivitas kerja (Masyhud, 2014: 132).

Untuk lebih jelasnya, pembahasan hasil penelitian ini adalah sebagai berikut.

1. Perencanaan kegiatan pembinaan soft skill guru melalui kegiatan halaqoh untuk suksesi PPA di SD al-Irsyad alIslamiyyah Purwokerto

Guru SD/MI berbeda dengan guru SMP/MTs dan SMA/MA. Pembelajaran pada SMP/MTs dan SMA/MA diselenggarakan oleh guru mata pelajaran. Sedangkan pembelajaran pada SD/MI diselenggarakan oleh guru kelas. Suksesi PPA di SD al-Irsyad alIslamiyyah Purwokerto sangat ditentukan oleh guru kelas. Hal itu menjadikan pihak LPP al-Irsyad al-Islamiyyah Purwokerto 


$$
\text { reces }
$$

menetapkan kriteria/standar guru kelas di SD al-Irsyad alIslamiyyah Purwokerto sepeti berikut ini:

\begin{tabular}{|c|c|c|}
\hline Aspek & $\begin{array}{c}\text { Standar } \\
\text { Kompetensi }\end{array}$ & Indikator \\
\hline \multirow[t]{2}{*}{ Aqidah } & \multirow{2}{*}{$\begin{array}{l}\text { Keyakinan } \\
\text { dan } \\
\text { Perbuatan } \\
\end{array}$} & Bersih dari perbuatan syirik \\
\hline & & $\begin{array}{l}\text { Selalu berdoa untuk keberhasilan } \\
\text { dan kesuksesan siswa }\end{array}$ \\
\hline \multirow[t]{2}{*}{ Al Quran } & $\begin{array}{l}\text { Bacaan Al } \\
\text { Quran }\end{array}$ & $\begin{array}{l}\text { Mampu membaca dengan benar } \\
\text { dan tartil }\end{array}$ \\
\hline & $\begin{array}{l}\text { Hafalan Al } \\
\text { Quran }\end{array}$ & Mempunyai hafalan juz 30 \\
\hline Al Hadits & $\begin{array}{l}\text { Hafalan } \\
\text { Hadits }\end{array}$ & $\begin{array}{l}\text { Mampu menghafal } 15 \text { hadits } \\
\text { pilihan (SD) }\end{array}$ \\
\hline \multirow[t]{4}{*}{$\begin{array}{l}\text { Ibadah } \\
\text { Praktis }\end{array}$} & Wudhu & $\begin{array}{l}\text { Berwudhu dengan sempurna } \\
\text { sesuai dengan tuntunan rosul } \\
\text { dalam hadits-hadits shahih. }\end{array}$ \\
\hline & Shalat & $\begin{array}{l}\text { Melaksanakan shalat fardhu tepat } \\
\text { waktu dan berjamaah (ustadz) }\end{array}$ \\
\hline & Mandi & $\begin{array}{l}\text { Mampu mengajarkan cara mandi } \\
\text { dari hadadz besar sesuai dengan } \\
\text { tuntunan Nabi SAW }\end{array}$ \\
\hline & Puasa & $\begin{array}{l}\text { Melakukan puasa sunah minimal } 4 \\
\text { kali dalam sebulan }\end{array}$ \\
\hline $\begin{array}{l}\text { Doa dan } \\
\text { Dzikir }\end{array}$ & $\begin{array}{l}\text { Sesudah } \\
\text { Shalat }\end{array}$ & $\begin{array}{l}\text { Hafal bacaan doa dan dzikir setelah } \\
\text { shalat }\end{array}$ \\
\hline \multirow[t]{5}{*}{$\begin{array}{l}\text { Adab } \\
\text { Islami }\end{array}$} & Tidur & $\begin{array}{l}\text { Hafal doa akan tidur dan } \\
\text { melaksanakan sesuai adab }\end{array}$ \\
\hline & Bangun Tidur & $\begin{array}{l}\text { Hafal doa akan bangun tidur dan } \\
\text { melaksanakan sesuai adab }\end{array}$ \\
\hline & $\begin{array}{l}\text { Masuk dan } \\
\text { keluar WC }\end{array}$ & $\begin{array}{l}\text { Hafal doa masuk dan keluar WC } \\
\text { serta melaksanakan sesuai adab }\end{array}$ \\
\hline & Makan & $\begin{array}{l}\text { Hafal doa akan makan dan } \\
\text { melaksanakan sesuai adab }\end{array}$ \\
\hline & $\begin{array}{l}\text { Masuk dan } \\
\text { keluar rumah }\end{array}$ & $\begin{array}{l}\text { Hafal doa akan masuk dan keluar } \\
\text { rumah serta melaksanakan sesuai }\end{array}$ \\
\hline
\end{tabular}


recus

\begin{tabular}{|c|c|c|}
\hline Aspek & $\begin{array}{c}\text { Standar } \\
\text { Kompetensi }\end{array}$ & Indikator \\
\hline & & adab \\
\hline & $\begin{array}{l}\text { Masuk dan } \\
\text { keluar masjid }\end{array}$ & $\begin{array}{l}\text { Hafal doa masuk dan keluar } \\
\text { masjid serta melaksanakan sesuai } \\
\text { adab }\end{array}$ \\
\hline & Bepergian & $\begin{array}{l}\text { Hafal doa akan bepergian dan } \\
\text { melaksanakan sesuai adab }\end{array}$ \\
\hline & Berpakaian & $\begin{array}{l}\text { Hafal doa berpakaian tidur dan } \\
\text { melaksanakan sesuai adab }\end{array}$ \\
\hline & Bertamu & $\begin{array}{l}\text { mampu melaksanakan bertamu/ } \\
\text { menerima tamu sesuai adab }\end{array}$ \\
\hline & $\begin{array}{l}\text { Ta'ziyah dan } \\
\text { menjenguk } \\
\text { orang sakit }\end{array}$ & $\begin{array}{l}\text { Hafal doa shalat jenazah } \\
\text { Hafal doa untuk orang sakit }\end{array}$ \\
\hline \multirow[t]{4}{*}{$\begin{array}{l}\text { Wawasan } \\
\text { Islam }\end{array}$} & \multirow[t]{2}{*}{ Sejarah Islam } & $\begin{array}{l}\text { Faham sejarah Nabi Muhammad } \\
\text { SAW }\end{array}$ \\
\hline & & $\begin{array}{l}\text { Faham sejarah perkembangan } \\
\text { Islam }\end{array}$ \\
\hline & \multirow[t]{2}{*}{ Patriotisme } & $\begin{array}{l}\text { Memiliki kepedulian terhadap } \\
\text { permaslahan muslim }\end{array}$ \\
\hline & & $\begin{array}{l}\text { Menampilkan sikap semangat } \\
\text { amar ma'ruh dan nahi mungkar }\end{array}$ \\
\hline \multirow[t]{7}{*}{$\begin{array}{l}\text { Kepribadia } \\
\mathrm{n}\end{array}$} & Jujur & $\begin{array}{l}\text { Memiliki kesamaan anara lisan, } \\
\text { hati, dan perbuatan }\end{array}$ \\
\hline & Kerjasama & $\begin{array}{l}\text { Mampu bekerjasama dan aktif } \\
\text { dalam kegiatan sekolah }\end{array}$ \\
\hline & Disiplin & Tidak pernah terlambat $(0 \%)$ \\
\hline & Sosialisasi & $\begin{array}{l}\text { Mampumenempatkan diri dalam } \\
\text { kelompok guru/siswa/orang tua }\end{array}$ \\
\hline & Komunikasi & $\begin{array}{l}\text { Tegas, jelas, dan santun baik secara } \\
\text { lisan maupun tulisan. }\end{array}$ \\
\hline & $\begin{array}{l}\text { Tanggung } \\
\text { jawab }\end{array}$ & $\begin{array}{l}\text { Selalu tuntas dalam melakukan } \\
\text { tugas dan kewajiban }\end{array}$ \\
\hline & Empati & $\begin{array}{l}\text { Mampu dan mau terlibat dalam } \\
\text { permasalahan siswa sebagai cara }\end{array}$ \\
\hline
\end{tabular}




\begin{tabular}{|c|c|c|}
\hline Aspek & $\begin{array}{c}\text { Standar } \\
\text { Kompetensi }\end{array}$ & Indikator \\
\hline & & menyelesaikan maslah siswa. \\
\hline \multirow{3}{*}{$\begin{array}{l}\text { Mengenal } \\
\text { Diri } \\
\text { Sendiri }\end{array}$} & \multirow[t]{2}{*}{ Pemahaman } & $\begin{array}{l}\text { Mengenal kelebihan dan } \\
\text { kekurangan diri }\end{array}$ \\
\hline & & $\begin{array}{l}\text { Mampu mengoptimalkan kelebihan } \\
\text { diri }\end{array}$ \\
\hline & Aplikasi & $\begin{array}{l}\text { Memiliki tujuan jelas terhadap } \\
\text { aktivitasnya }\end{array}$ \\
\hline \multirow[t]{12}{*}{$\begin{array}{l}\text { Kewalikela } \\
\text { san }\end{array}$} & \multirow[t]{4}{*}{ Performa } & $\begin{array}{l}\text { Mampu membangun Jati diri } \\
\text { manejer/Wali kelas. }\end{array}$ \\
\hline & & $\begin{array}{l}\text { Mampu } \\
\text { memantau/mengondisikan } \\
\text { penampilan siswa (pakaian, } \\
\text { assesoris, bahasa dan sikap) }\end{array}$ \\
\hline & & $\begin{array}{l}\text { Mampu mengevaluasi Guru dan } \\
\text { merekomendasikan kepada atasan } \\
\text { terkait dengan pembelajaran }\end{array}$ \\
\hline & & $\begin{array}{l}\text { Terdepan dalam pelaksanaan biah } \\
\text { di sekolah }\end{array}$ \\
\hline & \multirow{4}{*}{$\begin{array}{l}\text { Kegiatan } \\
\text { Rutin }\end{array}$} & Memiliki sikap konsisten diri. \\
\hline & & $\begin{array}{l}\text { Melakukan Tarhib-taudi', absensi } \\
\text { siswa, pagi ceria, istirahat }\end{array}$ \\
\hline & & $\begin{array}{l}\text { Memiliki Sikap kepedulian yang } \\
\text { tinggi terhadap siswa }\end{array}$ \\
\hline & & $\begin{array}{l}\text { Teknik Administrasi efektif dan } \\
\text { efisien }\end{array}$ \\
\hline & \multirow[t]{4}{*}{$\begin{array}{l}\text { Bimbingan } \\
\text { dan konseling }\end{array}$} & $\begin{array}{l}\text { Memahami usia perkembangan } \\
\text { siswa di kelasnya }\end{array}$ \\
\hline & & $\begin{array}{l}\text { Memahami identitas siswa satu } \\
\text { per satu (latar belakang keluarga, } \\
\text { pergaulan dan pola belajar) }\end{array}$ \\
\hline & & $\begin{array}{l}\text { Mampu melaksanakan alur } \\
\text { penanganan Kasus/masalah. }\end{array}$ \\
\hline & & $\begin{array}{l}\text { Mampu melakukan pencegahan } \\
\text { timbulnya masalah siswa. }\end{array}$ \\
\hline
\end{tabular}




\begin{tabular}{|c|c|c|}
\hline Aspek & $\begin{array}{c}\text { Standar } \\
\text { Kompetensi }\end{array}$ & Indikator \\
\hline & & $\begin{array}{l}\text { Mampu menyelesaikan masalah } \\
\text { siswa }\end{array}$ \\
\hline & & Mampu membuat Portofolio Siswa \\
\hline & Parenting & $\begin{array}{l}\text { Mampu berkomunikasi efektif } \\
\text { dengan orangtua dan tamu. }\end{array}$ \\
\hline & $\begin{array}{l}\text { Kontrol } \\
\text { Sistem }\end{array}$ & $\begin{array}{l}\text { Mampu mengontrol dan } \\
\text { mengevaluasi keberhasilan guru } \\
\text { mata pelajaran dalam mengajar }\end{array}$ \\
\hline & & $\begin{array}{l}\text { Memantau ketuntasan akademik } \\
\text { dan non akademik. }\end{array}$ \\
\hline & Administrasi & \begin{tabular}{lcr} 
Membuat & \multicolumn{2}{c}{ administrasi } \\
kewalikelasan yang $\quad$ bersifat \\
aksesbilitas dan validitas
\end{tabular} \\
\hline \multirow[t]{4}{*}{$\begin{array}{l}\text { Kepemimp } \\
\text { inan }\end{array}$} & Perencanaan & $\begin{array}{l}\text { Mampu merencanakan sebuah } \\
\text { program }\end{array}$ \\
\hline & $\begin{array}{l}\text { Pengorganisa } \\
\text { sian }\end{array}$ & $\begin{array}{l}\text { Mampu menjadi ketua suatu } \\
\text { kegiatan }\end{array}$ \\
\hline & Pelaksanaan & $\begin{array}{l}\text { Dapat melaksanakan kegiatan } \\
\text { sesuai proposal }\end{array}$ \\
\hline & $\begin{array}{l}\text { Pengontrolan } \\
\text { dan evaluasi }\end{array}$ & $\begin{array}{l}\text { Mampu melakukan pengontrolan } \\
\text { dan membuat evaluasi kegiatan }\end{array}$ \\
\hline \multirow[t]{2}{*}{$\begin{array}{l}\text { Kemampu } \\
\text { an rata- } \\
\text { rata }\end{array}$} & Penghargaan & $\begin{array}{lcr}\text { Memiliki } & \text { penghargaan } & \text { minimal } 1 \\
\text { kegiatan } & \text { internal } & \text { ataupun } \\
\text { eksternal } & & \\
\end{array}$ \\
\hline & $\begin{array}{l}\text { Perlombaan } \\
\text { atau } \\
\text { pertandingan }\end{array}$ & $\begin{array}{l}\text { Mengikuti perlombaan atau } \\
\text { pertandingan minimal } 3 \text { kali baik } \\
\text { internal atau eksternal }\end{array}$ \\
\hline \multirow[t]{2}{*}{ Akademis } & Pendidikan & Memiliki ijazah minimal strata-1 \\
\hline & $\begin{array}{l}\text { Jurusan/keah } \\
\text { lian }\end{array}$ & $\begin{array}{l}\text { Sebagai guru yang bersertifikat } \\
\text { baik standar internal atau } \\
\text { eksternal melalui pendidikan } \\
\text { formal }\end{array}$ \\
\hline Bahasa & $\begin{array}{l}\text { Bahasa } \\
\text { Indonesia }\end{array}$ & $\begin{array}{l}\text { Memiliki kecepatan membaca } 500 \\
\text { kata per menit }\end{array}$ \\
\hline
\end{tabular}




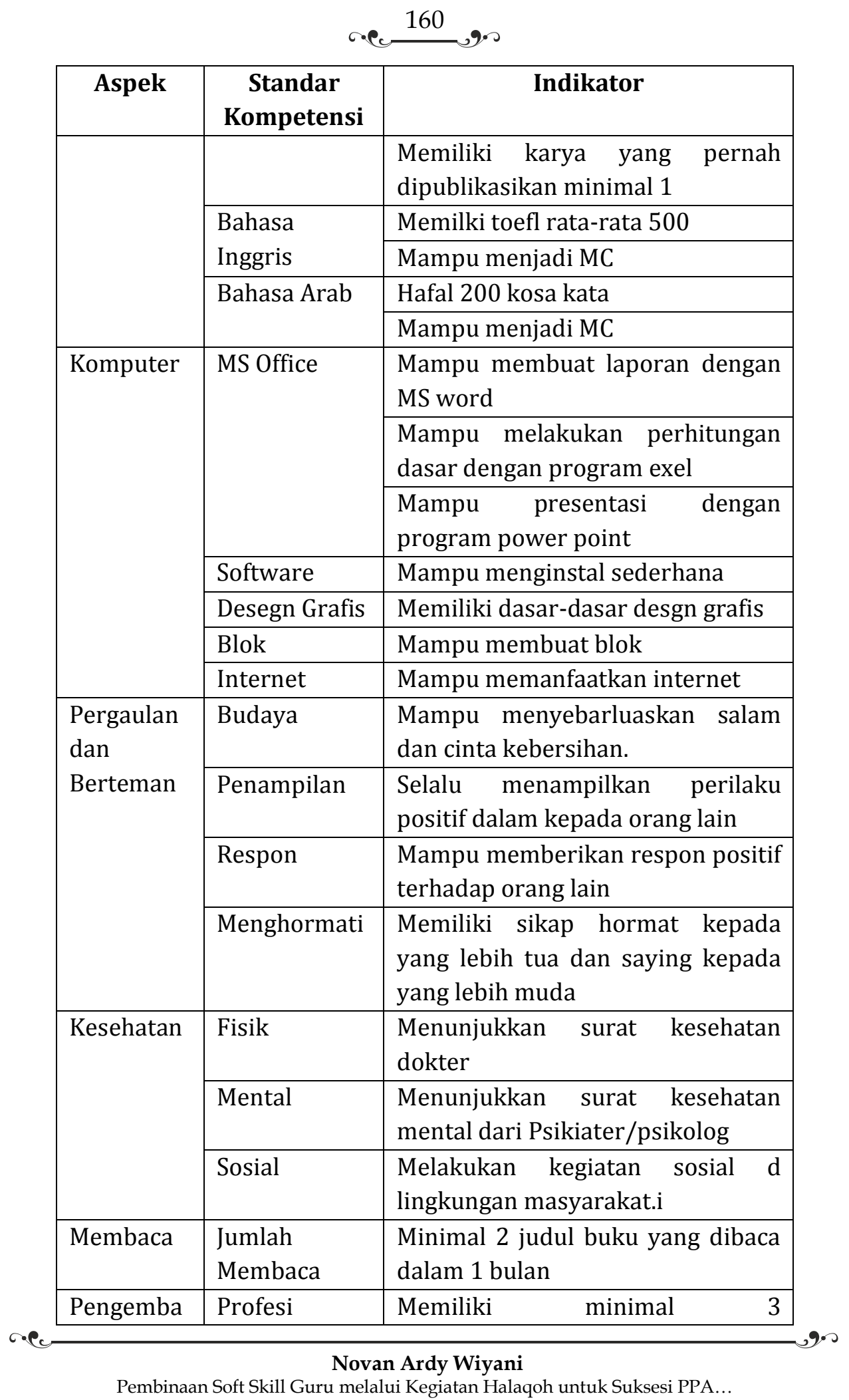




\begin{tabular}{|l|l|ll|}
\hline \multicolumn{1}{|c|}{ Aspek } & \multicolumn{1}{|c|}{$\begin{array}{c}\text { Standar } \\
\text { Kompetensi }\end{array}$} & \multicolumn{1}{|c|}{ Indikator } \\
\hline ngan & & $\begin{array}{l}\text { setifikat/piagam yang terkait } \\
\text { dengan profesinya }\end{array}$ \\
\cline { 2 - 4 } & Umum & $\begin{array}{l}\text { Memiliki tambahan minimal 1 } \\
\text { diluar profesinya. }\end{array}$ \\
\hline
\end{tabular}

Dari tabel standar guru kelas di atas sangat jelas bahwa aspek soft skill guru sangat mendominasi dibandingkan aspek hard skill. Aspek soft skill tersebut mencangkup pengamalan aqidah, al-Quran, hadits, ibadah praktis, doa dan dzikir, adab Islami, wawasan Islam, kepribadian, kemampuan mengenal diri sendiri, praktik kepemimpinan, serta etika pergaulan dan berteman.

Harapannya standarisasi tersebut dapat mendukung kesuksesan PPA. Kegiatan halaqoh pun diprogramkan bagi guru untuk memenuhi standarisasi guru kelas dan mensukseskan program PPA. Penanggung jawab bidang biah Islamiyyah yang bertugas menciptakan dan mengembangkan lingkungan SD alIrsyad al-Islamiyyah Purwokerto yang islami ditunjuk sebagai koordinator kegiatan halaqoh.

Penanggungjawab bidang biah Islamiyyah menentukan waktu pelaksanaan kegiatan halaqoh. Kegiatan ini diagendakan dilaksanakan satu minggu sekali pada hari Rabu jam 18.15 hingga 20.30 di masjid al-Ishlah dengan ketentuan alokasi waktu sebagai berikut:

a. Setelah maghrib hingga isya'

1) Pembukaan 5 menit.

2) Muraja'ah 10 menit.

3) Tahfidz 15 menit.

b. Setelah Isya'

1) Kultum tafsir 15 menit.

2) Materi inti 30 menit.

3) Materi tambahan 15 menit.

Berdasarkan agenda kegiatan halaqoh yang telah ditentukan kemudian penanggungjawab bidang biah Islamiyyah menyusun 


\section{r.e.c. 162}

jadwal petugas halaqoh. Berikut adalah sampel jadwal petugas halaqoh yang telah disusun oleh penanggungjawab bidang biah Islamiyyah:

\begin{tabular}{|c|c|c|c|c|c|c|}
\hline \multirow[b]{2}{*}{ No } & \multirow[b]{2}{*}{ Tanggal } & \multicolumn{2}{|c|}{ Petugas } & \multirow[b]{2}{*}{$\begin{array}{l}\text { Materi } \\
\text { Kultum }\end{array}$} & \multirow[b]{2}{*}{ Muroja'ah } & \multirow{2}{*}{$\begin{array}{c}\text { Cek } \\
\text { Hafalan } \\
\text { Oleh } \\
\text { Mu'allim }\end{array}$} \\
\hline & & $\begin{array}{c}\text { MC \& } \\
\text { Muroja'ah }\end{array}$ & Kultum & & & \\
\hline 1. & $\begin{array}{l}22 \text { Januari } \\
2014\end{array}$ & Tri Setiadi & Sufyan & $\begin{array}{c}\text { Tafsir } \\
\text { Surat } \\
\text { Quroisy }\end{array}$ & $\begin{array}{c}\text { Al Mursalat, } \\
\text { Al Insan }\end{array}$ & Tri Setiadi \\
\hline 2. & $\begin{array}{l}29 \text { Januari } \\
2014\end{array}$ & Sutrisno & Tri Setiadi & $\begin{array}{c}\text { Tafsir } \\
\text { Surat Al- } \\
\text { Fiil }\end{array}$ & $\begin{array}{l}\text { Al Qiyamah, } \\
\text { Al Muddatsir }\end{array}$ & Sutrisno \\
\hline 3. & $\begin{array}{c}5 \\
\text { Februari } \\
2014\end{array}$ & Yanto & Sutrisno & $\begin{array}{c}\text { Tafsir } \\
\text { Surat Al- } \\
\text { Humazah }\end{array}$ & $\begin{array}{c}\text { Al } \\
\text { Muzzammil, } \\
\text { Al Jin }\end{array}$ & Yanto \\
\hline 4. & $\begin{array}{c}12 \\
\text { Februari } \\
2014 \\
\end{array}$ & Misbah & Yanto & $\begin{array}{c}\text { Tafsir } \\
\text { Surat Al- } \\
\text { 'Ashr }\end{array}$ & $\begin{array}{l}\text { Nuh, Al } \\
\text { Ma'arij }\end{array}$ & Misbah \\
\hline 5. & $\begin{array}{c}19 \\
\text { Februari } \\
2014\end{array}$ & Alfiyan & Misbah & $\begin{array}{c}\text { Tafsir } \\
\text { Surat At- } \\
\text { Takatsur }\end{array}$ & $\begin{array}{c}\text { Al Haaqqoh, } \\
\text { Al Qolam }\end{array}$ & Alfiyan \\
\hline 6. & $\begin{array}{c}26 \\
\text { Februari } \\
2014\end{array}$ & Zaenal A & Alfiyan & $\begin{array}{c}\text { Tafsir } \\
\text { Surat Al- } \\
\text { Qori'ah }\end{array}$ & Al Mulk & Zaenal A \\
\hline 7. & $\begin{array}{c}5 \text { Maret } \\
2014\end{array}$ & Heriyanto & Zaenal A & $\begin{array}{c}\text { Tafsir } \\
\text { Surat Al- } \\
\text { 'Adiyat }\end{array}$ & At-Tahrim & Heriyanto \\
\hline 8. & $\begin{array}{c}12 \text { Maret } \\
2014\end{array}$ & Kurniawan & Heriyanto & $\begin{array}{c}\text { Tafsir } \\
\text { Surat Al- } \\
\text { Zalzalah }\end{array}$ & At-Thalaq & Kurniawan \\
\hline 9. & $\begin{array}{l}19 \text { Maret } \\
2014\end{array}$ & Hurip P & Kurniawan & $\begin{array}{c}\text { Tafsir } \\
\text { Surat Al- } \\
\text { Bayyinah }\end{array}$ & At-Taghabun & Hurip P \\
\hline 10. & $\begin{array}{l}26 \text { Maret } \\
2014\end{array}$ & Arian S & Hurip P & $\begin{array}{c}\text { Tafsir } \\
\text { Surat Al- } \\
\text { Qodr }\end{array}$ & $\begin{array}{c}\text { Al- } \\
\text { Munafiqun }\end{array}$ & Arian S \\
\hline 11. & $\begin{array}{l}2 \text { April } \\
2014\end{array}$ & Supriyanto & Arian S & $\begin{array}{c}\text { Tafsir } \\
\text { Surat Al- } \\
\text { 'Alaq }\end{array}$ & Al-Jumu'ah & Supriyanto \\
\hline 12. & $\begin{array}{l}9 \text { April } \\
2014\end{array}$ & $\begin{array}{c}\text { Ari } \\
\text { Nurhidayat }\end{array}$ & Supriyanto & $\begin{array}{c}\text { Tafsir } \\
\text { Surat At- } \\
\text { Tin }\end{array}$ & Ash-Shaff & $\begin{array}{c}\text { Ari } \\
\text { Nurhidayat }\end{array}$ \\
\hline 13. & $\begin{array}{c}16 \text { April } \\
2014\end{array}$ & Sufyan & $\begin{array}{c}\text { Ari } \\
\text { Nurhidayat }\end{array}$ & $\begin{array}{c}\text { Tafsir } \\
\text { Surat Al- } \\
\text { Insyiroh }\end{array}$ & $\begin{array}{l}\text { Al Mursalat, } \\
\text { Al Insan }\end{array}$ & Sufyan \\
\hline 14. & $\begin{array}{c}23 \text { April } \\
2014\end{array}$ & Tri Setiadi & Sufyan & $\begin{array}{l}\text { Tafsir } \\
\text { Surat }\end{array}$ & $\begin{array}{l}\text { Al Qiyamah, } \\
\text { Al Muddatsir }\end{array}$ & Tri Setiadi \\
\hline
\end{tabular}

Pembinaan Soft Skill Guru melalui Kegiatan Halaqoh untuk Suksesi PPA... 


\begin{tabular}{|c|c|c|c|c|c|c|}
\hline & & & $\begin{array}{c}\text { Adh- } \\
\text { Dhuhaa }\end{array}$ & & \\
\hline 15. & $\begin{array}{c}30 \text { April } \\
2014\end{array}$ & Sutrisno & Tri Setiadi & $\begin{array}{c}\text { Tafsir } \\
\text { Surat Al- } \\
\text { Lail }\end{array}$ & $\begin{array}{c}\text { Al } \\
\text { Muzzammil, } \\
\text { Al Jin }\end{array}$ & Sutrisno \\
\hline 16. & $\begin{array}{c}7 \text { April } \\
2014\end{array}$ & Yanto & Sutrisno & $\begin{array}{c}\text { Tafsir } \\
\text { Surat Asy- } \\
\text { Syams }\end{array}$ & $\begin{array}{c}\text { Nuh, Al } \\
\text { Ma'arij }\end{array}$ & Yanto \\
\hline 17. & $\begin{array}{c}14 \text { April } \\
2014\end{array}$ & Misbah & Yanto & $\begin{array}{c}\text { Tafsir } \\
\text { Surat Al- } \\
\text { Balad }\end{array}$ & $\begin{array}{c}\text { Al Haaqqoh, } \\
\text { Al Qolam }\end{array}$ & Sufyan \\
\hline
\end{tabular}

Kemudian untuk memastikan agar pelaksanaan halaqoh nantinya berjalan sesuai harapan, disusunlah Standard Operating Procedures (SOP) kegiatan halaqoh. Pada SOP tersebut ditetapkan ketentuan kegiatan tahfidz dan tahsin, ketentuan kegiatan kultum tafsir, ketentuan kegiatan materi inti dan ketentuan kegiatan materi tambahan.

2. Pengorganisasian kegiatan pembinaan soft skill guru melalui kegiatan halaqoh untuk suksesi PPA di SD al-Irsyad alIslamiyyah Purwokerto

Kegiatan pengorganisasian dilakukan untuk membagi tugas antara kepala sekolah, musyrif (ketua kelompok halaqoh), dan mu'allim (pengisi materi halaqoh). Tugas kepala sekolah dalam pelaksanaan kegiatan halaqoh untuk membina soft skill guru yaitu melakukan pemantauan guru ketika mengikuti kegiatan halaqoh, memberikan arahan kepada guru peserta kegiatan halaqoh, serta memberi teguran pada guru yang tidak mengikuti kegiatan halaqoh. Sedangkan tugas musyrif antara lain:

a. Mengabsensi kehadiran peserta pembinaan.

b. Mengumpulkan tugas dari dari peserta pembinaan.

c. Mengatur kegiatan penunjang pembinaan seperti jadwal kultum, kegiatan mabit, dan lain-lain.

d. Melaporkan rekap kehadiran dan tugas ke biah Islamiyyah setiap dua pekan.

e. Bersama muallim memantau dan mengevaluasi kegiatan tahsin, dan tahfidz peserta halaqoh secara maksimal.

f. Merekap dan melaporkan pantauan tahsin dan tahfidz peserta halaqoh kepada biro islamiyyah setiap dua pekan. 


$$
\text { r.e. } 164
$$

Sedangkan tugas mu'allim yaitu memimpin kegiatan tahsin dan tahfidz, menyampaikan materi kultum dan tafsir al-Qur'an, serta memotivasi guru untuk lebih ikhlas dan bekerja keras membentuk karakter peserta didik yang qur'ani serta berakhlak baik kepada guru, orang tua dan lingkungan.

\section{Pelaksanaan kegiatan pembinaan soft skill guru melalui kegiatan halaqoh untuk suksesi PPA di SD al-Irsyad al- Islamiyyah Purwokerto}

Pelaksanaan kegiatan pembinaan soft skill guru melalui kegiatan halaqoh pada dasarnya merupakan upaya yang dilakukan untuk mencapai tujuan dari kegiatan halaqoh. Tujuan dari dilaksanakannya kegiatan halaqoh antara lain:
a. Sebagai ajang silaturahmi antar guru.
b. Sebagai wadah sharing antar guru.
c. Membentuk guru yang berakhlak mulia.

Halaqoh secara bahasa berarti lingkaran. Sedangkan secara istilah kegiatan halaqoh adalah kegiatan diskusi yang diikuti oleh sekelompok orang yang duduk dalam posisi melingkar. Kegiatan diskusi tersebut dipimpin oleh seorang mu'allim. Kegiatan halaqoh di SD al-Irsyad al-Islamiyyah Purwokerto wajib diikuti oleh guru sebagai SDM sekolah. Satu kelompok halaqoh terdiri dari 15 orang guru.

Kegiatan halaqoh dilaksanakan dengan mengkaji dan berdiskusi tentang materi tentang tafsir al-Qur'an, materi keislaman serta tahsin dan tahfidz Qur'an. Selain itu dalam pelaksanaan kegiatan halaqoh dilakukan pula sharing tentang bagaimana cara mengatasi masalah-masalah dalam mendidik peserta didik di sekolah, khususnya dalam rangka membentuk peserta didik yang berakhlak mulia.

Manfaat yang diperoleh guru dari pelaksanaan kegiatan halaqoh adalah kualitas dan kuantitas ibadahnya menjadi terkontrol. Hafalan al-Qur'annya juga menjadi terkontrol. Hal itu menjadikan soft skill guru SD al-Irsyad al-Islamiyyah Purwokerto selalu terbaharukan.

Kemanfaatan tersebut berimplikasi pada kesuksesan Program Pendidikan Akhlak (PPA) bagi peserta didik di SD alIrsyad al-Islamiyyah Purwokerto. Output dari pelaksanaan 


$$
\text { res }
$$

kegiatan halaqoh untuk membina soft skill guru adalah guru yang berakhlak mulia. Guru yang berakhlak mulia bisa menjadi teladan bagi peserta didik, sehingga ia dapat dijadikan sebagai panutan oleh peserta didik dalam berperilaku.

Tidak mungkin dapat terbentuk peserta didik yang berakhlak mulia jika gurunya tidak berakhlak mulia. Dengan kata lain, pembentukan peserta didik yang berakhlak mulia harus diawali dengan pembentukan guru yang berakhlak mulia terlebih dahulu. Di sinilah urgensi pembinaan soft skill bagi guru dalam suksesi Program Pendidikan Akhlak (PPA) di SD al-Irsyad alIslamiyyah Purwokerto.

Setidaknya ada tiga faktor pendukung dalam pelaksanaan kegiatan halaqoh untuk membina soft skill guru di SD al-Irsyad alIslamiyyah Purwokerto, yaitu:

a. Ada peran musyrif yaitu ketua kelompok yang selalu memantau kegiatan ubudiyah sehari-hari para guru.

b. Ada buku pantuan ibadah yang harus dilaporkan setiap satu bulan sekali kepada musyrif dan diketahui oleh kepala sekolah.

c. Ada sanksi bagi guru yang tidak mengikuti kegiatan halaqoh sehingga kedisiplinan guru terlatih dan terbentuk.

Sedangkang faktor penghambat dalam pelaksanaan kegiatan halaqoh untuk membina soft skill guru di SD al-Irsyad alIslamiyyah Purwokerto antara lain:

a. Kegiatan halaqoh dilaksanakan malam hari sehingga banyak guru yang sudah kelelahan karena seharian full bekerja di sekolah.

b. Ada guru yang sering mengalami bentrok jadwal antara kegiatan halaqoh dengan kegiatan lainnya.

4. Pengontrolan kegiatan pembinaan soft skill guru melalui kegiatan halaqoh untuk suksesi PPA di SD al-Irsyad alIslamiyyah Purwokerto

Ada dua bentuk pengontrolan kegiatan pembinaan soft skill guru melalui kegiatan halaqoh untuk suksesi PPA di SD al-Irsyad al-Islamiyyah Purwokerto. Pertama, pemantauan yang dilakukan oleh kepala sekolah. Dalam hal ini kepala sekolah memantau kehadiran guru dalam kegiatan halaqoh, apa ada yang jarang berangkat atau tidak ada. Jika ada guru yang jarang berangkat 


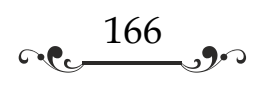

tanpa alasan tertentu atau udzur syar'i maka kepala sekolah akan memberikan arahan maupun teguran kepadanya.

Kedua, pemantauan yang dilakukan oleh mu'allim. Mu'allim memantau dan mengevaluasi kegiatan tahsin dan tahfidz serta memantau ibadah harian guru satu pekan sekali. Jika ditemukan guru yang ibadah hariannya tidak sesuai harapan maka mu'allim akan memberikan arahan dan motivasi. Misalnya ketika ayat-ayat dalam tadarus yang dibaca kurang dan hafalannya menurun maka akan dimotivasi untuk lebih giat lagi dalam menghafal al-Qur'an. Mu'allim tidak memberikan sanksi kepada guru yang mengalami masalah dalam praktik ubudiyahnya. Mu'allim bertindak sebagai mitra untuk membantu guru dalam mengatasi masalah tersebut.

\section{Simpulan}

Kegiatan halaqoh adalah kegiatan diskusi yang diikuti oleh sekelompok orang yang duduk dalam posisi melingkar. Tujuan dari dilaksanakannya kegiatan halaqoh yaitu sebagai ajang silaturahmi antar guru, sebagai wadah sharing antar guru, dan membentuk guru yang berakhlak mulia. Untuk mencapai tujuan tersebut disusunlah rencana kegiatan pembinaan soft skill guru melalui kegiatan halaqoh. Rencana tersebut tertuang pada penetapan tujuan, standarisasi guru, penyusunan agenda kegiatan halaqoh, jadwal petugas halaqoh dan SOP halaqoh. Berdasarkan rencana yang telah disusun dilakukanlah pengorganisasian kegiatan pembinaan soft skill guru melalui kegiatan halaqoh dengan melakukan pembagian tugas pada kepala sekolah, musyrif, dan mu'allim.

Kemanfaatan yang didapat dari pelaksanaan kegiatan pembinaan soft skill guru melalui kegiatan halaqoh adalah kualitas dan kuantitas ibadahnya menjadi terkontrol. Hafalan al-Qur'annya juga menjadi terkontrol. Hal itu menjadikan soft skill guru SD alIrsyad al-Islamiyyah Purwokerto selalu terbaharukan. Kemanfaatan tersebut berimplikasi pada kesuksesan Program Pendidikan Akhlak (PPA) bagi peserta didik di SD al-Irsyad alIslamiyyah Purwokerto.

Kemudian untuk memastikan bahwa jalannya kegiatan halaqoh ini dapat mengarah pada tujuan yang telah ditetapkan 


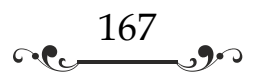

dilakukanlah kegiatan pengontrolan. Kegiatan pengontrolan dilakukan oleh kepala sekolah dan mu'allim. Kepala sekolah mengontrol kehadiran guru pada kegiatan halaqoh, sedangkan mu'allim mengontrol kegiatan tahsin dan tahfidz serta ibadah harian guru.

Berdasarkan hasil penelitian ini maka penulis mengajukan rekomendasi kepada pihak SD al-Irsyad al-Islamiyyah Purwokerto sebagai berikut:

a. Menyelenggarakan kegiatan halaqoh bukan pada jam istirahat guru.

b. Membuat modul materi halaqoh dan didistribusikan kepada semua guru peserta kegiatan halaqoh.

c. Kegiatan halaqoh tidak hanya dilaksanakan di masjid, tetapi juga bisa dilaksanakan di tempat lain misalnya di sekolah, di kantor yayasan, dan di rumah guru secara bergiliran. 


\section{reces}

\section{Daftar Pustaka}

Masyhud, Sulthon. 2014. Manajemen Profesi Kependidikan. Yogyakarta: Kurnia Kalam Semesta.

Moleong, Lexy J. 2012. Metodologi Penelitian Kualitatif. Bandung: Rosda.

Mudlofir. 2012. Pendidik Profesional: Konsep, Strategi dan Aplikasinya dalam Peningkatan Mutu Pendidikan di Indonesia. Jakarta: Rajawali Press.

Ramayulis dan Samsul Nizar. 2009. Filsafat Pendidikan Islam: Telaah Sistem Pendidikan dan Pemikiran Para Tokohnya. Jakarta: Kalam Mulia.

Rochman, Chaerul dan Heri Gunawan. 2012. Pengembangan Kompetensi Kepribadian Guru: Menjadi Guru yang Dicintai dan Diteladani oleh Siswa. Bandung: Nuansa Cendekia.

Salam, Abdus. 2014. Manajemen Insani dalam Pendidikan. Yogyakarta: Pustaka Pelajar.

Sulistyorini. 2009. Manajemen Pendidikan Islam: Konsep, Strategi dan Aplikasi. Yogyakarta: Teras.

Tobroni. 2015. Pendidikan Islam: dari Dimensi Paradigma Teologis, Filosofis, dan Spiritualitas hingga Dimensi Praksis Normatif. Jakarta: Mitra Wacana Media.

Wahjosumidjo. 2011. Kepemimpinan Kepala Sekolah: Tinjauan Teoritik dan Permasalahannya. Jakarta: Raja Grafindo Persada. 